\title{
Note on the Transliteration of Arabic and Turkish
}

This book is based mainly on Arabic and Ottoman Turkish sources. Since Ottoman was written in Arabic script, many of the words share the same spelling. Turkish pronunciation, however, is markedly different from Arabic. In transliteration I have tried to follow the original language of the source or sources.

Arabic terms are transliterated according to the rules of the International Journal of Middle East Studies. Terms in Turkish are rendered in modern Romanized Turkish orthography. In this system, $c$ is pronounced as $j$ in English; $c ̧$ is pronounced as $c h ; g$ is usually unvocalized and lengthens the preceding vowel; and $\imath$ (undotted $i$ ) is pronounced as the vowel $u$ in the word turn.

Where words in Ottoman do not have a well-known modern equivalent, or when the text relies heavily on Arabic, I have used Arabic diacritics in transliteration of Turkish.

In many cases, the same term is transliterated from both Ottoman and Arabic sources. As a rule, the transliteration follows the Arabic when Arabic sources were quoted and Turkish in the case of Ottoman Turkish sources. In other cases, when specified, the transliteration is used to make temporal or spatial distinctions. For instance, the term for Islamic law is transliterated as $\operatorname{shari~}^{-} a$ when referring to non-Ottoman practices, and as șeriat when referring to the system as practiced and elaborated under the Ottomans. 
